\title{
Effects of Training and Supervision on the Self-Efficacy of Psychology Graduate Teaching Assistants
}

\author{
Loreto R. Prieto \\ Counseling Psychology Program \\ University of Oklahoma
}

Steven A. Meyers

Roosevelt University

We surveyed psychology graduate teaching assistants (GTAs) to obtain information about their training and supervision and examined their sense of self-efficacy toward teaching as a function of these experiences. Results indicated that formal training has a positive, statistically significant effect on GTAs' sense of self-efficacy toward teaching. However, departments of psychology appear to offer GTAs formal training and supervision in an inconsistent manner.

The training and supervision of graduate teaching assistants (GTAs) is an important issue for departments of psychology to address (cf. Fernald, 1995); however, only recently have investigators begun to conduct research in this area. The few existing studies offer conflicting findings regarding the adequacy of psychology GTA training and rely solely on the report of psychology department chairs (e.g., Mueller, Perlman, McCann, \& McFadden, 1997). Furthermore, although major reviews of the literature suggest that training and supervising GTAs increases their acquisition and use of effective teaching behaviors (see Abbott, Wulff, \& Szego, 1989; Nyquist \& Wulff, 1996), virtually none of this research has been theory driven or focused primarily on psychology GTAs. As such, investigators have yet to identify the process and mechanisms by which training and supervision benefit psychology GTAs. Therefore, it may be helpful to begin examining psychology GTA training and supervision issues by using a theory-driven approach and directly sampling psychology GTAs regarding their actual experiences.

Self-efficacy, or the degree to which people estimate their ability to perform a necessary behavior successfully to bring about a desired outcome (efficacy expectations; Bandura, 1986), has long been hypothesized to be a strong mediating variable in teacher effectiveness. For example, Denham and Michael (1981) suggested that teachers' sense of efficacy is not only affected by the training they receive and teaching experiences they encounter but also that their sense of efficacy directly affects their observable behaviors and performance in the classroom. According to Denham and Michael's conceptual model, a heightened sense of self-efficacy should affect teachers' perceived and actual abilities to teach more effectively.

Self-efficacy is affected by four main forces that include (a) performance accomplishments, (b) modeling or vicarious learning, (c) verbal persuasion, and (d) emotional arousal. However, self-efficacy theory holds that performance accomplishments, or successfully executing desired behaviors, are the best way to develop and maintain new behavioral skills (Bandura, 1986). As such, training programs for psychology GTAs that provide direct, teaching-based activities such as developing microteaching skills and delivering practice lectures (cf. Meyers, 1998) should inculcate a sense of self-efficacy in novice instructors by allowing them to learn core teaching skills in a setting where they can build a sense of success and mastery. Vicarious learning, verbal persuasion, and emotional arousal can also contribute to behavior acquisition and maintenance but in a more indirect fashion (Bandura, 1986). For example, GTA self-efficacy can be influenced by training and supervision activities such as having GTAs observe other instructors teaching (modeling or vicarious learning), providing GTAs with supervisory pep talks to help manage their classroom performance anxieties (verbal persuasion), or fostering high levels of determination in GTAs to work through the difficulties in their duties (emotional arousal). Empirical studies support the conceptual relations between teacher self-efficacy and performance in the classroom (for a review, see Dembo \& Gibson, 1985). Similar findings have been reported in research that focuses directly on GTAs, especially concerning the significantly positive effect that training has on GTA self-efficacy and classroom performance (Bray \& Howard, 1980; Prieto \& Altmaier, 1994).

Thus, the available literature suggests that training as well as teaching experience appear to increase GTA self-efficacy with regard to acquiring and employing effective teaching behaviors; however, these relations have yet to be confirmed for psychology GTAs. Furthermore, the effect of supervision on GTA self-efficacy is unknown. Last, studies concerning psychology department chairs' reports regarding the adequacy of psychology GTA training and supervision have generated conflicting findings. Studies that have reported findings based on data obtained from only those departments where GTA training and supervision actually occur (e.g., Mueller et al., 1997) have created a more positive impression of the current state of affairs than have the results of investigations that were based on larger sample sizes and also accounted for departments where GTA training and supervision did not exist 
(e.g., Meyers et al., 1997). Therefore, this study sought to clarify these issues by directly sampling psychology GTAs regarding their training and supervision experiences and also by examining whether formal training and supervision significantly increased psychology GTAs' sense of self-efficacy toward teaching.

\section{Method}

\section{Procedures and Participants}

Chairs of the 259 psychology departments listed in Graduate Study in Psychology (American Psychological Association, 1996) received and were asked to distribute materials to GTAs in their department. One hundred and seventy-six psychology GTAs returned usable data and were included in this study, representing a total of 116 different psychology departments. Percentages of the psychology departments responding with usable data from each national region (cf. U.S. Department of Commerce, 1993) were: Midwest (48\%), Northeast (35\%), South (46\%), and West (44\%), thereby providing a reasonably balanced national sample.

The sample consisted of 113 women (64\%) and 63 men $(36 \%)$ with a mean age of $28.6(S D=5.87)$. The majority of participants reported their racial-ethnic background as being Euro American (82\%) and reported pursuing the doctorate degree $(86 \%)$ in the subspecialties of clinical $(38 \%)$, social $(14 \%)$, or combined programs $(13 \%)$. Participants reported a mean of six semesters $(S D=3.9)$ of previous graduate education and a mean of three semesters $(S D=3.0)$ of previous teaching experience as a GTA. The vast majority of participants reported having either full responsibility for their courses $(38 \%)$ or adjunctive teaching duties (supporting the professor's teaching; 51\%). The remaining $11 \%$ reporting having only nonteaching, administrative duties as a part of their assistantship or did not indicate the type of GTA position they held.

\section{Instruments}

SETI-A. The Self-Efficacy Towards Teaching Inventory-Adapted (SETI-A; Prieto \& Altmaier, 1994; for the original SETI, see Tollerud, 1990) is a 32 item, self-report measure that assesses the degree to which respondents feel confident in their ability to execute specific teaching behaviors across various teaching domains (e.g., course preparation, instructor behavior, managing course materials, and evaluation). Items have a 4-point Likert scale format, using polar anchors of 1 (not confident) to 4 (completely confident) for each of the teaching behaviors listed. The SETI-A generates a total summed score ranging from 32 to 128 . We obtained a Cronbach alpha coefficient of .93 for the current SETI-A data, which matches that obtained in past research (cf. Prieto \& Altmaier, 1994).

Demographic questionnaire. A brief instrument solicited demographic data concerning participants' GTA training (e.g., time spent, topics covered), teaching (e.g., number of courses, type of appointment), and supervision experiences (e.g., frequency and format of supervision).

Results

\section{GTA Training and Supervision Variables}

Sixty-eight percent of the sample had received training for their current GTA duties and reported spending an average total of $22 \mathrm{hr}(\mathrm{SD}=22 \mathrm{hr})$ in training activities. The most frequently reported training activities were watching faculty or veteran GTAs model teaching techniques and attending workshops on teaching techniques or theory. Sixty-two percent of the participants received supervision of their GTA duties, usually in a weekly individual supervision meeting with the instructor of record for the course. With regard to the co-occurrence of training and supervision, $47 \%$ received either training or supervision for their GTA duties, 40\% received both training and supervision for their GTA duties, and $13 \%$ of the sample received no training or supervision of any kind.

\section{Analyses of Interest}

A preliminary ANOVA indicated that mean SETI-A scores of GTAs varied significantly according to their level of teaching duties (i.e., full, adjunctive, or nonteaching), $F(2$, $168)=5.21, p<.01$. A Tukey-HSD post hoc follow-up test $(p<.05)$ indicated that GTAs in nonteaching positions had a significantly lower mean SETI-A score than GTAs with teaching responsibilities and also indicated that the mean SETI-A scores of GTAs with full and adjunctive teaching duties did not differ significantly. Therefore, the data from the participants holding nonteaching GTA positions and from participants who did not indicate the type of GTA position they held were not included in later analyses. Furthermore, the data from the two groups of GTAs with teaching-based positions (full and adjunctive) were pooled for further analyses of interest $(n=157)$. Bonferroni-corrected correlational analyses on this reduced sample indicated that previous teaching experience was related to SETI-A scores, $r(156)=.18, p<.03$; participant age was also related to self-efficacy scores, $r(156)=.27, p<.001$. Participant age was also related to previous teaching experience, $r(155)=.36, p<.001$. These results suggested colinearity among these three variables. To assess the unique effects of training and supervision on GTA self-efficacy, we used participant age as a covariate to control for the effect of previous teaching experience on SETI-A scores in an ANCOVA.

We conducted a $2 \times 2$ ANCOVA on SETI-A scores, using the presence or absence of training and supervision as independent variables. The covariate of participant age accounted for a significant amount of variance, $F(1,148)=$ $10.4, p<.002$, and a unique, significant main effect was found for training, $F(1,148)=5.1, p<.025$. Neither a main effect for supervision nor a significant interaction effect were found. These results indicated that, regardless of their previ- 
ous amount of teaching experience, psychology GTAs who received formal training had significantly higher self-efficacy toward teaching than those psychology GTAs who did not receive formal training.

\section{Discussion}

We surveyed psychology GTAs across the nation to obtain information concerning their training and supervision and to determine how these experiences affected their sense of self-efficacy toward their teaching duties. The current descriptive results disagree with reports that suggest psychology GTAs are adequately and consistently trained and supervised (cf. Mueller et al., 1997). Instead, with approximately $30 \%$ of our sample having received either no training or no supervision, our findings support investigations that suggest GTAs receive inconsistent training and supervision in departments of psychology (cf. Meyers et al., 1997). With regard to the effects of training and supervision on self-efficacy, psychology GTAs who received formal training possessed a greater sense of self-efficacy toward their teaching duties than those psychology GTAs who did not receive such training. These findings support and encourage the training efforts now in place for psychology GTAs and highlight the importance of formally preparing psychology GTAs for their teaching responsibilities.

Noteworthy is the fact that GTAs reported spending more training time on observational or didactic activities (more indirect methods of influencing efficacy) as opposed to teaching-based activities such as delivering practice lectures and receiving feedback (more direct methods of influencing efficacy). Given that performance accomplishments are most likely to contribute to higher levels of self-efficacy (Bandura, 1986), training and supervision techniques that directly focus on practicing actual teaching-based activities might be more beneficial, especially for beginning GTAs (cf. Prieto, 1995). Surprisingly, ongoing supervision did not have a significant effect on GTA self-efficacy. However, this study did not account for the quality of the supervision received by GTAs or other similar factors that may be more salient predictors of self-efficacy than simply the presence or absence of supervision. Some researchers in the area of GTA supervision have suggested that varying the difficulty and complexity of GTAs' role demands in accordance with their level of teaching experience and mastery may help to optimize GTAs' sense of self-efficacy (cf. Prieto, 1995).

Overall in this study, we underscore the importance of GTA training and offer preliminary support for the use of self-efficacy theory to conceptualize the skill development of psychology GTAs; however, additional research is needed. If producing professional psychologists who are well-rounded and capable scientist-practitioner-educators is a desirable goal, then the training and supervision of psychology GTAs must become more consistent. Moreover, the search for the most effective ways to carry out GTA training and supervi- sion must become a priority for all graduate departments of psychology.

\section{References}

Abbott, R. D., Wulff, D. H., \& Szego, K. (1989). Review of research on TA training. In J. D. Nyquist, R. D. Abbott, \& D. H. Wulff (Eds.), Teaching assistant training in the 1990s: Number 39. New directions for teaching and learning (pp. 111-124). San Francisco: Jossey-Bass.

American Psychological Association. (1996). Graduate study in psychology (29th ed.).Washington, DC: Author.

Bandura, A. (1986). Social foundations of thought and action. New York: Prentice-Hall.

Bray, J. H., \& Howard, G. S. (1980). Methodological considerations in the evaluation of a teacher-training program. Journal of Educational Psychology, 72, 62-70.

Dembo, M. H., \& Gibson, S. (1985). Teacher's sense of efficacy: An important factor in school improvement. The Elementary School Journal, 86, 173-184.

Denham, C. H., \& Michael, J. J. (1981). Teacher sense of efficacy: A definition of the construct and a model for further research. Educational Research Quarterly, 5, 39-61.

Fernald, P.S. (1995). Preparing psychology graduate students for the professoriate. American Psychologist, 50, 421-427.

Meyers, S. A. (1998, May). Techniques to develop the teaching skills of psychology graduate students and faculty. Paper presented at the annual meeting of the Midwestern Psychological Association, Chicago.

Meyers, S. A., Prieto, L. R., Fishman, E., Rajecki, D. W., Quina, K., \& Massoth, N. (1997, August). Teaching assistant training in departments of psychology: A national survey. Poster presented at the annual meeting of the American Psychological Association, Chicago.

Mueller, A., Perlman, B., McCann, L. I., \& McFadden, S. H. (1997). A faculty perspective on teaching assistant training. Teaching of Psychology, 24, 167-171.

Nyquist, J. D., \& Wulff, D. H. (1996). Working effectively with graduate assistants. Thousand Oaks, CA: Sage.

Prieto, L. R. (1995). Supervising graduate teaching assistants: An adaptation of the Integrated Developmental Model. Journal of Graduate Teaching Assistant Development, 2, 93-105.

Prieto, L. R., \& Altmaier, E. M. (1994). The relationship of prior training and previous teaching experience to self-efficacy among graduate teaching assistants. Research in Higher Education, 35, 481-497.

Tollerud, T. (1990). The perceived self-efficacy of teaching skills of advanced doctoral students and graduates from counselor education programs (Doctoral dissertation, University of Iowa, 1990). Dissertation Abstracts International, 51, 12A.

U.S. Department of Commerce. (1993). 1990 census of population: Social and economic characteristics (United States). Washington, DC: Author.

\section{Note}

Send correspondence to Loreto R. Prieto, Counseling Psychology Program, University of Oklahoma, Norman, OK 73019-2041; e-mail: lprieto@ou.edu. 